\title{
الهجمة الاستيطانية غير المسبوقة هي مشروع حكومة نتنياهو الوحيد غيرة
}

يمثّـل كلٌّل مـن الاسـتيطان واحتـلال الأرض العربيـة قيمـة أساسـية عليـا فـي الأيديولـوجيـة الصهيونيـة، ويحتلّان أهمية قصوى في سياسـات مختلف التيارات الصهيونية سـواء كانت

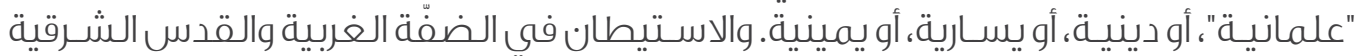
المحتلّة، سياسة إسرائيلية كولـونيالية مركزية ثابتة، تسعىى إسرائيل من خلالها إلى تحقيقية

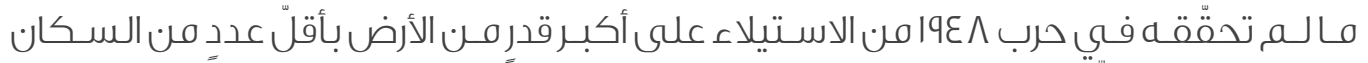
العرب؛ أفما إن احتلّت إسرائيل بقيّية الأراضي العربية الفلسطَينية في حرب حزيران / يونيو

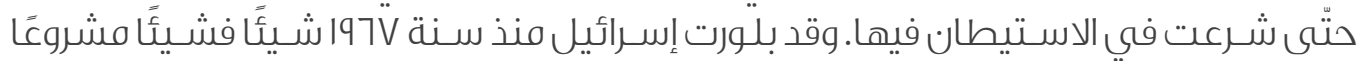
استيطانيّا كولونياليّا في الأراضي العربية الفلسطينية المحتلّة. تناقش هذه الورقة سياسية ساسة

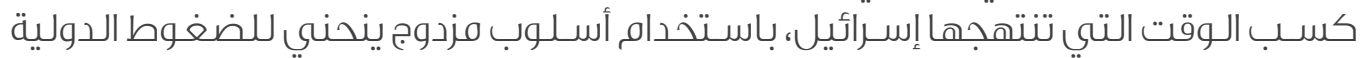

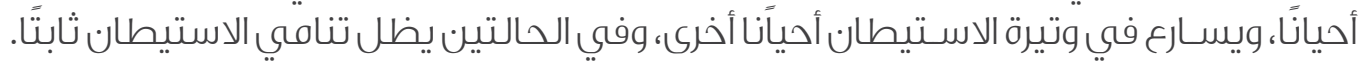

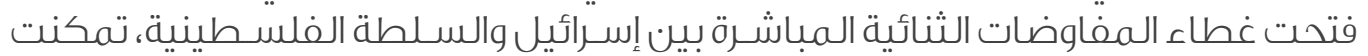

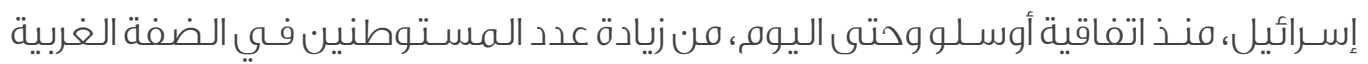
المحتلة ثلاثة أضعاف، وعدد المستوطنين في القدس الشرقية المحتلة مرّتين. 
من 1 مأور استيطانية أقامتها الحكومات الإسرائيلية المتعاقبة في

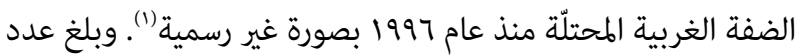

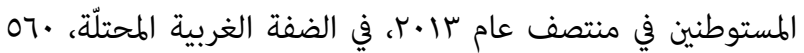
ألف مستوطن؛ منهم ·. · ألف مستوطن في مدينة القدس الشرقية

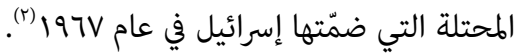
ومن املاحظ أنّ الحكومات الإسرائيلية المتعاقبة استعملت في العقدين ونيف الماضيين ما يُطلق عليه "المسيرة السلمية"، والمفاوضات الثنائية المباشرة بينها وبين السلطة الفلسطينية، لتصبح أفضل غطاء لاستمرار

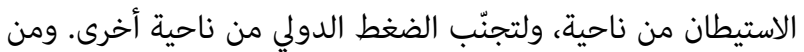

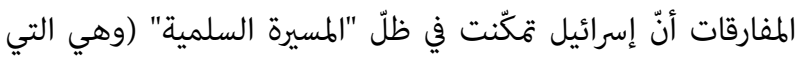

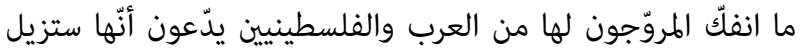
الاحتلال والاستيطان)، وتحت غطاء المفاوضات الثنائية المباشرة بين

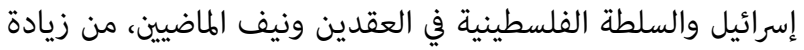

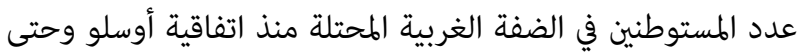
اليوم ثلاثة أضعاف، ومضاعفة عدد المستوطنين مرّتين في القدس الفعه الفريه

الشرقية المحتلة (ب).

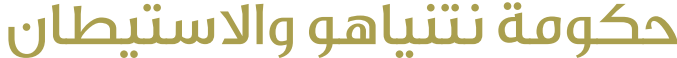

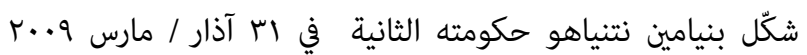

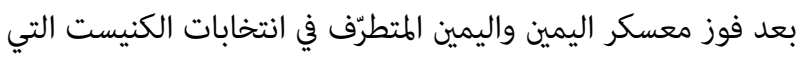
جرت في بداية ذلك العام (وكانت الأولى في سنوات 1997 - 1999). وبعد مرور أربعة أعوام، جرت انتخابات عامّة للكنيست الإسرائيلي

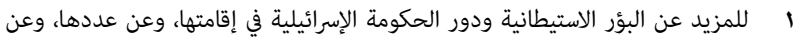

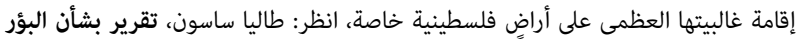

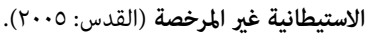

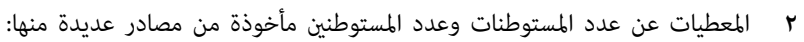

مكتب الإحصاء المركزي الإسرائيلي، على الرابط: http://www.cbs.gov.il/shnaton62/st02_13.pdf

والجهاز المركزي للإحصاء الفلسطيني، على الرابط: http://www.pcbs.gov.ps/Portals/_pcbs/PressRelease/settlmt2011A.pdf وموقع حركة السلام الآن، على الرابط: - مابط

http://peacenow.org.il/node/297

وموقع عير عميم، على الرابط:

http://www.ir-amim.org.il/?CategoryID=464

r م للمزيد عن الاستيطان وتاريخه ودور الحكومات الإسرائيلية والمؤسسة العسكرية في تعزيزه،

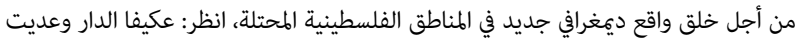

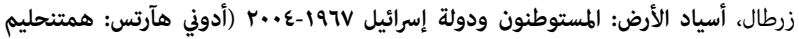

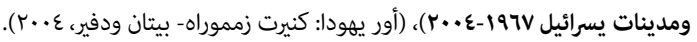

دأبت إسرائيل على رعاية الاستيطان وتعزيزه عامًا بعد آخر. وسرعان

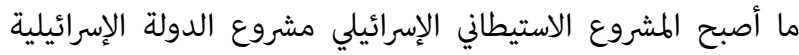

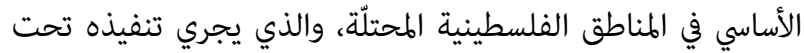

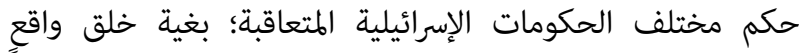

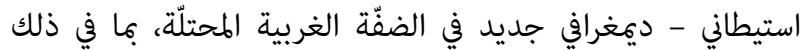

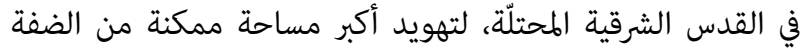
الغربية المحتلّة، ومن ثَمْ ضمّها.

تحكّمت مجموعة من العوامل المهمّة في وتيرة زيادة الاستيطان في الضفّة الغربية المحتلّة، ولا تزال تتحكّم فيها، وفي مقدمتها سياستا التهويد والتوسّع اللتان ما انفكّت تلتزم بهما جميع الحكومات الإسرائيلية؛ واللتان تحظيان بتأييدٍ واسع في المجتمع الإسرائيلي، ولا سيّما لدى المؤسسة العسكرية ومعظم الأحزاب السياسية وجماعات الضغط، والقوى الاستيطانية الفاعلة في المجتمع مهما اختلفت الحكومات. وفي المقابل، يحذّ كلّ من الضغط الـدولي والمقاومة الفلسطينية من وتيرة الاستيطان؛ إذ لوحظ تباطؤ في وتيرة الاستيطان إبّان الانتفاضتين الأولى والثانية. وعندما تتعرّض الحكومات الإسرائيلية

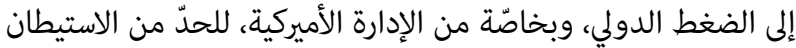

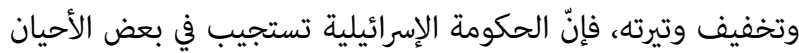
لهذه الضغوط، ولكنّها في الوقت نفسه تستمرّ في الاستيطان بوتيرة لا تقود إلى صدامِ وقطيعة كاملة مع الإدارة الأميركية والمجتمع الدولي،

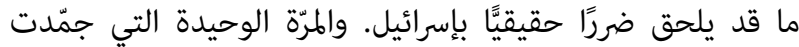
فيها إسرائيل شكليَّا الاستيطان في المناطق الفلسطينية المحتلّة، لمدّة

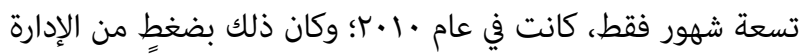

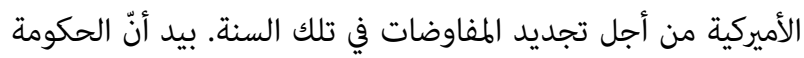

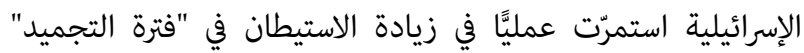

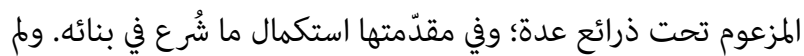

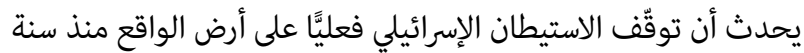

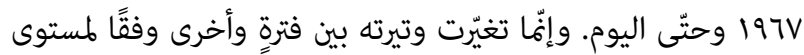
المقاومة على الأرض، ودرجة الضغوط الدولية.

يبلغ عدد المستوطنات في الضفّة الغربية المحتلة ععا مستوطنة أقامتها الحكومات الإسرائيلية المتعاقبة بصورة رسمية؛ منها ستّ

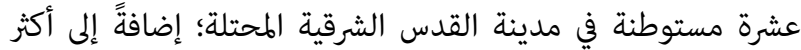


بالملاحظة أنّ rrا ب من هذه الوحدات السكنية الاستيطانية - أي

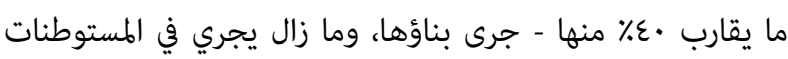

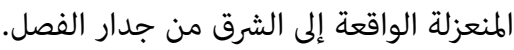

ثانيًا، أعلن في هذه الفترة عن عطاءات لبناء r.باه وحدة سكنية

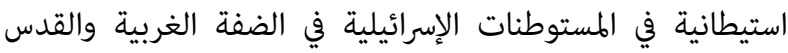

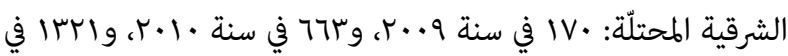

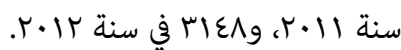

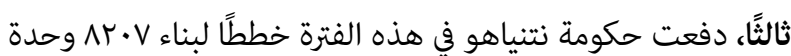

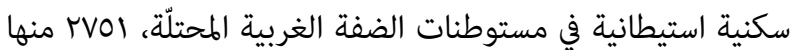

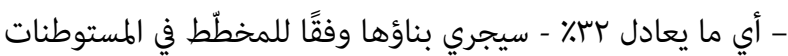

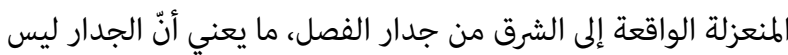

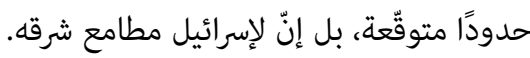
ع - قنّنت حكومة نتنياهو في هذه الفترة عشر بؤرِ استيطانية

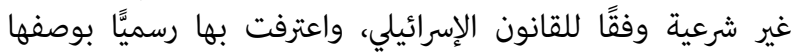

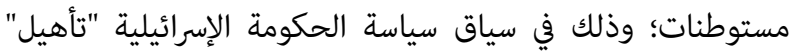

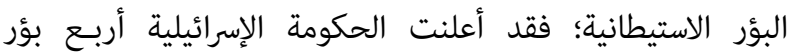

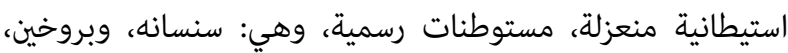

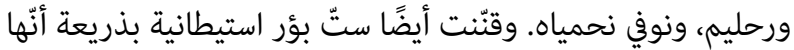

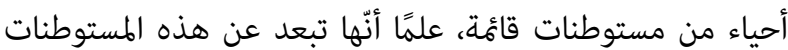

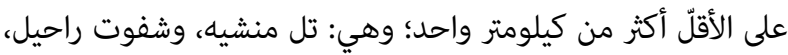
ومتسبيه اشتمواع، وجفعات سلعيت، والمتان، وعفور ميغرون. إلى

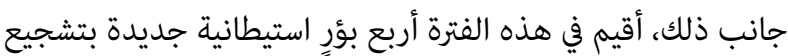

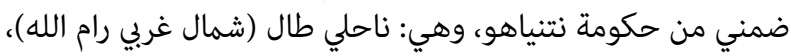
وتسوفيم تسفون (شمال مدينة قلقيلية)، ونحلات يوسف (بالقرب

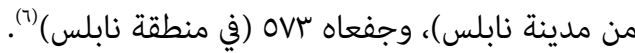

\section{الاستيطان من مارس سرا. Г إلى نوفمبر سا.}

شهدت الـفـترة المــــــدّة منذ تشكيل نتنياهو الحكومة في

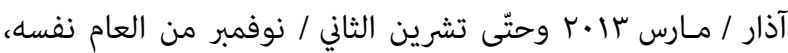
هجمة استيطانية غير مسبوقة في تاريخ الاستيطان الإسرائيلي؛ سواء

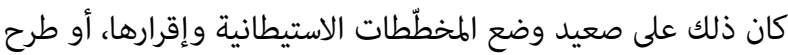

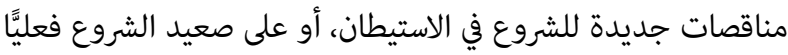

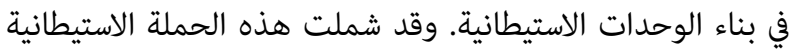

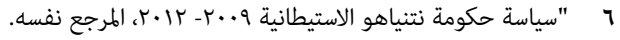

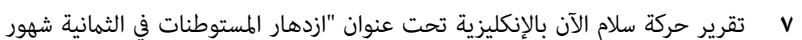

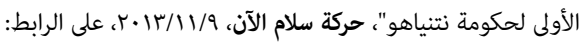

فاز فيها معسكر اليمين واليمين المتطرف، وشكّل بنيامين نتنياهو

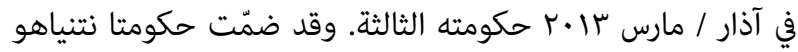

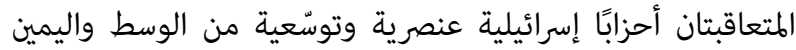
واليمين المتطرف الإسرائيلي الداعمة الاستيطان بشدّة؛ ما جعلها "حكومة مستوطنين" بكلّ ما تعنيه هذه الكلمة من معنى (ع). بعد عام ونصف العام من تعامل حكومة نتنياهو الثانية مع إدارة أوباما بحذر، حرص نتنياهو خلالها على عدم الصدام الحادّ معها بشأن إنان

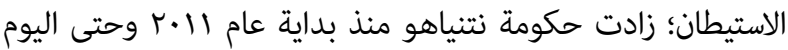

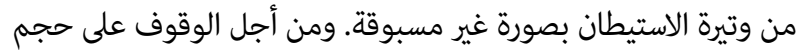

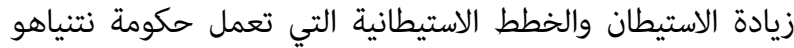

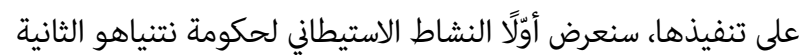

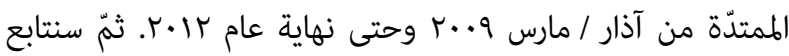
الموجة الاستيطانية غير المسبوقة منذ تشكيل حكومة نتنياهو الثالثة في

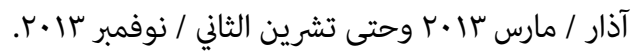

ضمّت حكومتا نتنياهو المتعاقبتان أحزابًا إســـرائيلية عنصرية وتوســـــية من الوســـــواليميــن واليمين المتطرف الإســـرائيلي الداعمة الاستيطان بشدّة؛ ما جعلها "حكومة مســـوطنين" بكلّ مـــ تعنيه هذه P الكلمة من معنى

\section{الاستيطان في الضفة الغربية من آذار/ مارس".}

شهدت هذه المرحلة هجمة استيطانية قثثّلت بما يلي (0): أوّلًا، شرعت حكومة نتنياهو في هذه المرحلة في بناء TNTV وحدة سكنية استيطانية في المستوطنات في الضفة الغربية المحتلّة. وجدير فئاه ع للمزيد انظر: "حكومة نتنياهو الجديدة أكثر تطرًِّا من حكومته السابقة"، موقع المركز

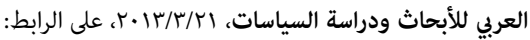
http://goo.gl/mlgTfi

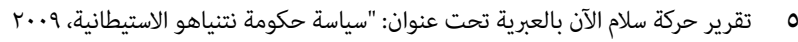

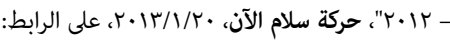
http://peacenow.org.il/sites/default/files/Summary4years_Heb.pdf

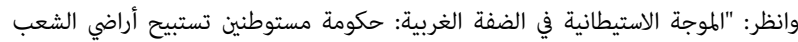

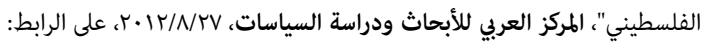
http://goo.gl/oKksHV 
بين بيت لحم والخليل في الضفة الغربية المحتلة. أمّا العنقود الثاني، فيشمل بناء . بV وحدة سكنية استيطانية في مستوطنة معليه

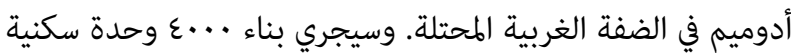
استيطانية في العنقود الثالث في منطقة مستوطنة عطروت الفعه (بالقرب من قلنديا) وفي مستوطنة تسور هداسا، القائمتين في القدس الشرقية

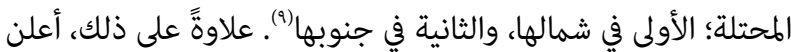
رئيس الحكومة الإسرائيلية بنيامين نتنياهو عزم الحكومة الإسرائيلية

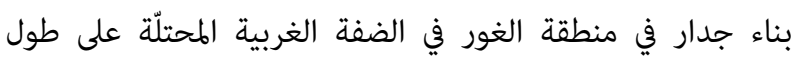

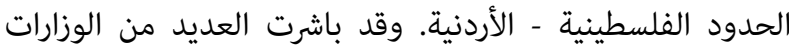

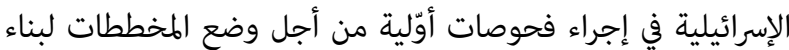

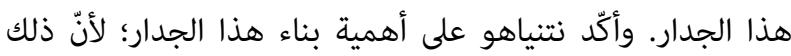

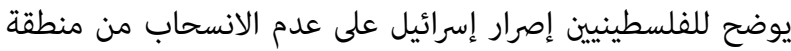
الغور في أيّ اتفاق مستقبلي بين إسرائيل والفلسطينيين، وأنّ إسرائيل تعدّ نهر الأردن حدّها الشرقي (1.).

ووصل الإعلان عن خطط الاستيطان إلى ذروته، عندما أعلن وزير البناء والإسكان الإسرائيلي أوري أريئيل (وهو من عناءن إلى ذروته عنداة المستوطنين) عن عطاءات لوضع خطط لبناء عب ألف وحدة سكنية استيطانية في الضفة الغربية المحتلة'"(1). وقد أثار هذا الإعلان ردود فعل أميركية ودولية شديدة، ما جعل رئيس الحكومة الإسرائيلية بنيامين نتنياهو يصدر أمرًا إلى الوزير أوري أريئيل بتجميد هذا المخطّط. يستهدف الاستيطان الإسرائيلي منطقتين فلسطينيتين واسعتين محتلّتين منذ عام $197 V$ بغرض تهويدهما؛ وهما المنطقة التي يطلَّق عليها

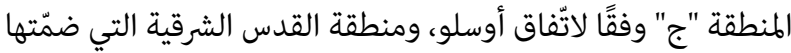
إسرائيل إليها في عام 197 مباشرةً بعد احتلالها.

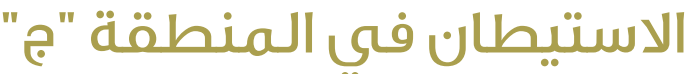

قسّمت اتفاقية أوسلو الضفّة الغربية المحتلة إلى ثلاث مناطق (علاوةً على القدس الشرقية المحتلة)، وهي:

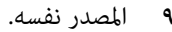

• اليلي بردشتاين، "في ظل الأزمة في المفاوضات: نتنياهو يعجّل البدء في إقامة الجدار في

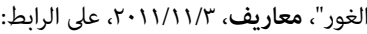
http://www.nrg.co.il/online/1/ART2/518/833.html?hp=1\&cat=404\&loc=1

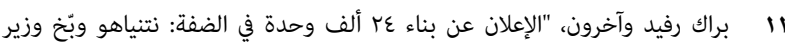

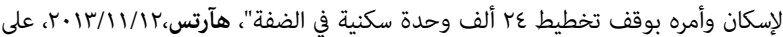

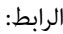

http://www.haaretz.co.il/news/politics/.premium-1.2164180
أوّلًا، أعلن في هذه الفترة عن عطاءات للبدء في بناء سكنية استيطانية في الضفة الغربية والقدس الشرقية المحتلّة، منها

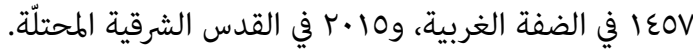

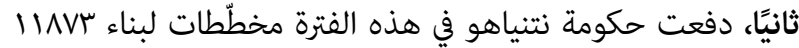
وحدة سكنية استيطانية في الضفّة الغربية والقدس الشرقية المحتلّة. ومن المهمّ الإثارة إلى أنّ توقيت الإعلان عن دفع هذه الفيطة المخطّطات،

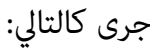

oOVV * الخمسة شهور التي سبقت البدء في المفاوضات بين إسرائيل والسلطة

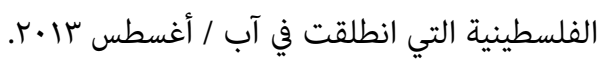

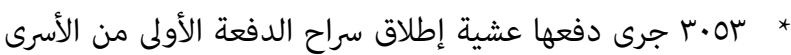
الفلسطينيين الذين بلغ عددهم حب أسيرًا. V07 * جرى دفعها خلال شهري المفاوضات التي تلت إطلاق الدفعة الأولى من الأسرى الفلسطينيين الذين بلغ عددهم حبر أسيرًا.

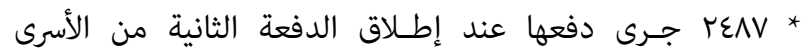
الفلسطينين.

إلى جانب كلّ ذلك، كشفت صحيفة "هآرتس" الإسرائيلية النقاب في

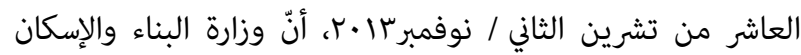

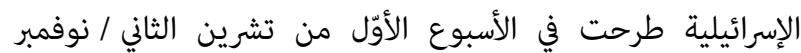

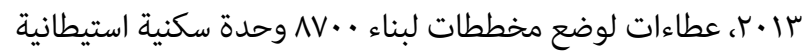

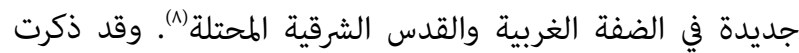

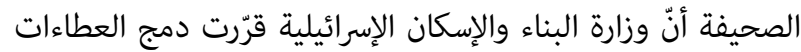
التي تطرحها لوضع مخطُطات البناء في المستوطنات، مع العطاءات

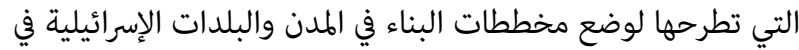

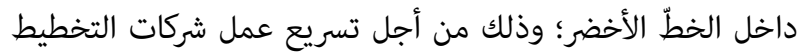

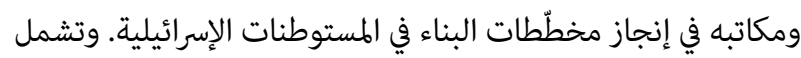
العطاءات التي طرحتها وزارة البناء والإسكان ثلاثة عناقيد. ويضمّ فئر إناء

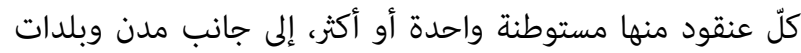

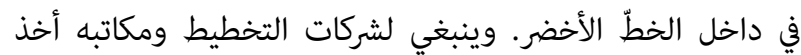

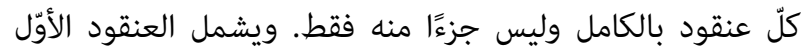
بناء ...1 وحدة سكنية استيطانية في مستوطنة جفعوت الواقعة فئة

\section{http://goo.gl/JAIaOw}

^ تسفرير رينات، "الشرط للفوز بمناقصات الدولة: ينبغي التخطيط أيضا للمستوطنات"،

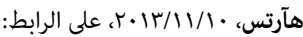
http://www.haaretz.co.il/news/science/.premium-1.2161218 


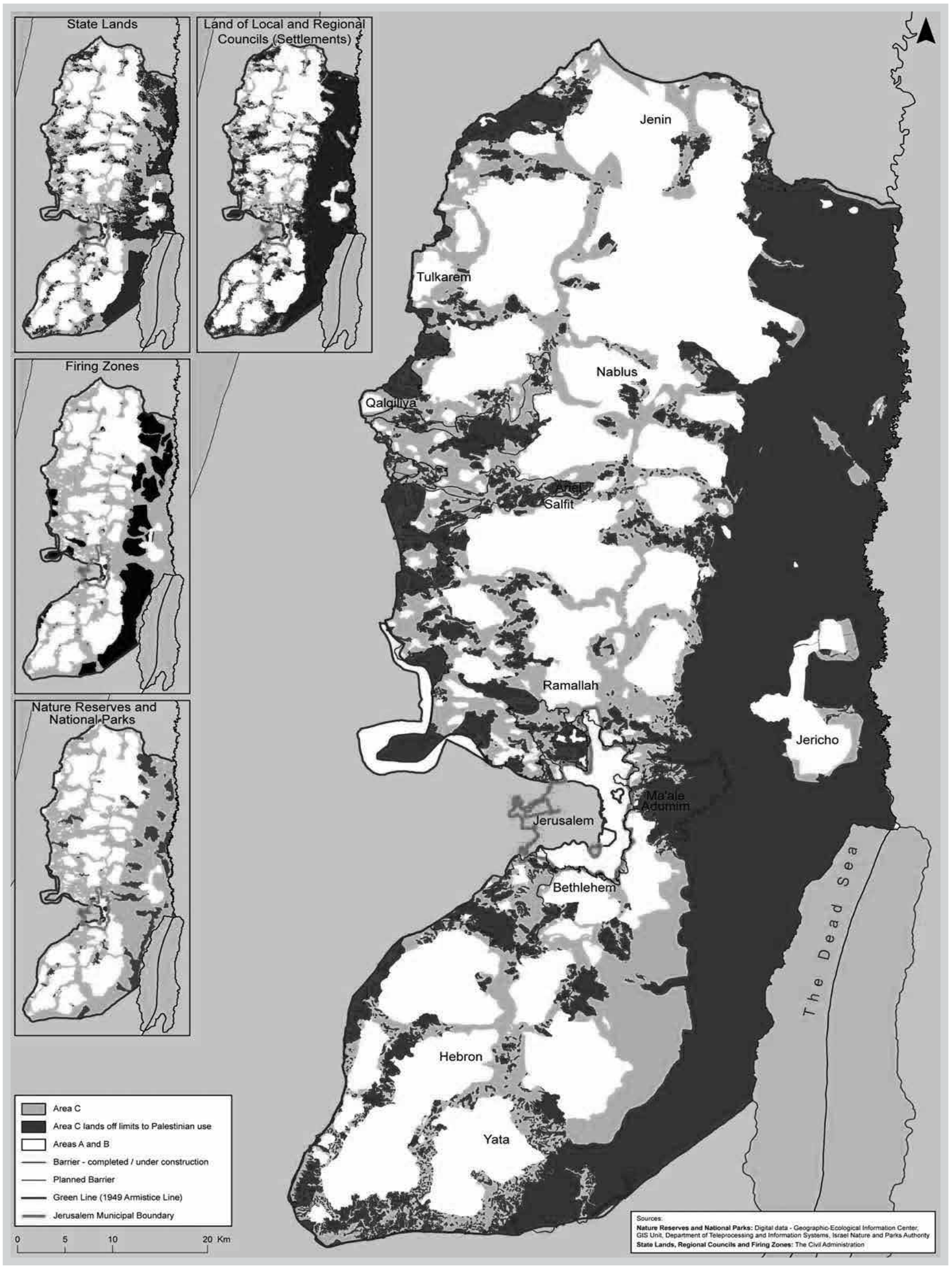


العسكري الذي تطبّقه على الفلسطينيين في الضفة الغربية المحتلّة. ليس هذا فحسب، بل يحظى المستوطنون ومستوطناتهم بالأفضلية

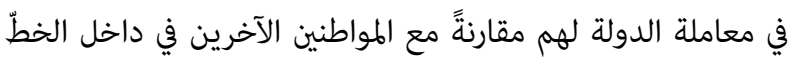

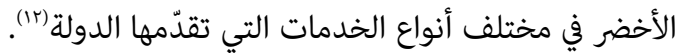
ويسيطر الاحتلال على الحيّز العامّ في المنطقة "ج" بصورة كاملة.

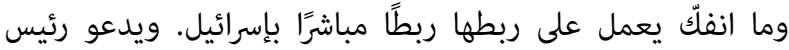
حزب البيت اليهودي الوزير نفتالي بنيت، الشريك المهمّ في الائتلاف

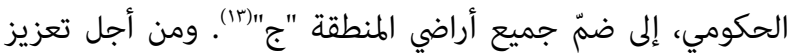

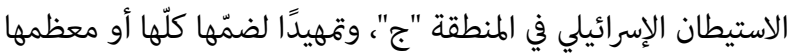

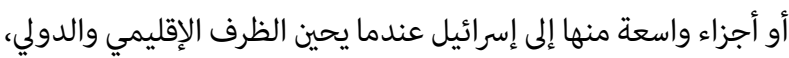
أقدمت سلطات الاحتلال الإسرائيلي على الخطوات التالية (ع): ا ـ أقام الاحتلال بنية تحتية اقتصادية وشبكة مائيّة وخطوط كهرباء وشبكة طرق، في العقدين الماضيين؛ لخدمة المستوطنات والمستوطنين

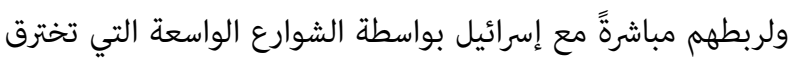
مختلف أرجاء هذه المنطقة عرضًا وطولًا. r. خصّصت سلطات الاحتلال سج٪ من مساحة المنطقة "ج"؛ بوصفها مناطق نفوذ تابعة للمجالس المحلّية وللمجالس الإقليمية للمستوطنات. وأعلنت سلطات الاحتلال أيضًا عن مليون و..r ألف دونم في هذه المنطقة بوصفها أراضي دولة، أي تابعة للاحتلال الإسرائيلي (10). ". أعلنت سلطات الاحتلال عن • ب٪ من مساحة المنطقة "ج" مناطق

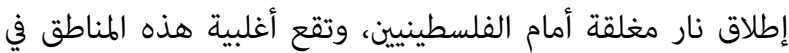

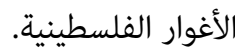

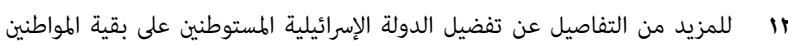

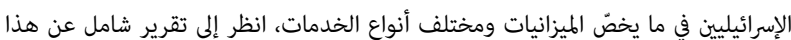

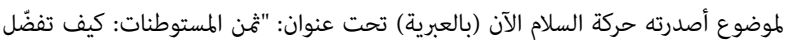

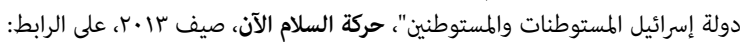
http://settlementwatcheastjerusalem.files.wordpress.com/2013/06/ settlementsbudgetnotebook.pdf

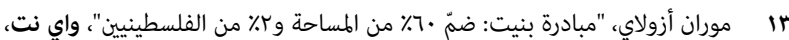

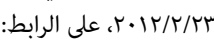
http://www.ynet.co.il/articles/0,7340,L-4193652,00.html

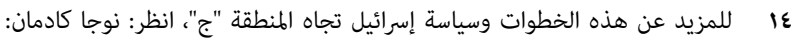

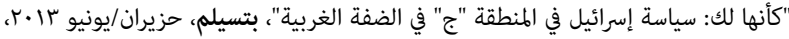

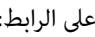

http://www.btselem.org/download/201306_area_c_report_heb.pdf 10 المرجع نفسه.
• المنطقة "أ": تبلغ مساحتها ^\٪ من مساحة الضفّة الغربية المحتلّة. وتشمل المدن الفلسطينية في الضفّة الغربية المحتلّة.

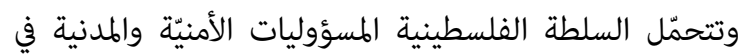

هذه المنطقة.

ه المنطقة "ب": تبلغ مساحتها rr٪ من مساحة الضفّة الغربية

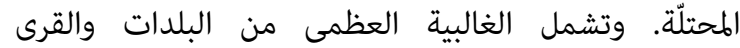
الفلسطينية في الضفة الغربية المحتلة. وتتحمّل السلطة الوطنية

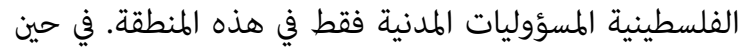
بقيت الصلاحيات الأمنيّة في يد سلطات الاحتلال الإسرائيلي. ه المنطقة "ج": تبلغ مساحتها •7\% من مساحة الضفّة الغربية

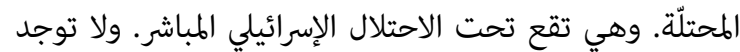

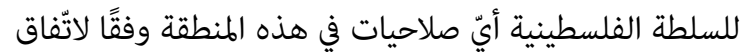

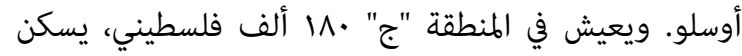

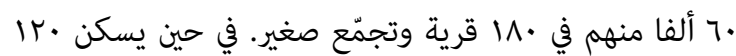

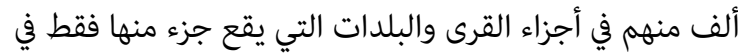

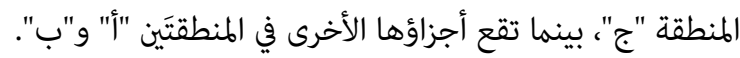

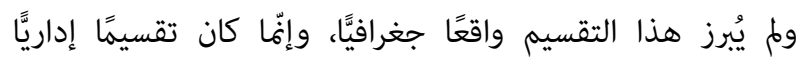

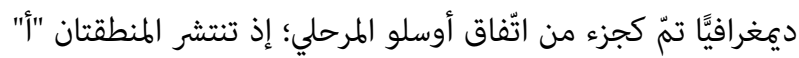

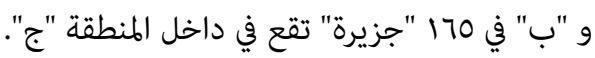
وسعت إسرائيل في تقسيمها الضفّة الغربية إلى المناطق "أ" و"ب"

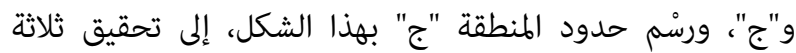

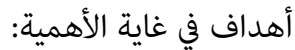

• كي يكون بداخل المنطقة "ج" جميع المستوطنات الإسرائيلية المقامة في الضفّة الغربية المحتلّة (باستثناء المستوطنات في

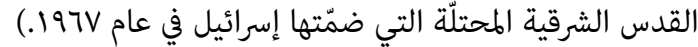
• لتخصيص هذه المنطقة للاستيطان الإسرائيلي فقط. • لحصر الفلسطينيين في المنطقتين "أ" و"ب"، وفصلهم عن أراضيهم وحقولهم ومزارعهم، والتي تمثّل احتياطيهم الأساسي في جميع القرى والبلدات والمدن الفلسطينية في الضفّة الغربية؛ لحرمانهم من النموّ والتطوّر في مختلف الميادين الاقتصادية والزراعية والصناعية والسياحية، وغيرها. تتعامل إسرائيل عمليًّا مع المنطقة "ج" بوصفها منطقة إسرائيلية بحكم الأمر الواقع، وليس بوصفها منطقة تحت الاحتلال. وتطبّق القانون الإسرائيلي على المستوطنين وعلى مستوطناتهم، وليس القانون 
وأطلقت عليها "بؤر استيطانية غير قانونية"، أو "بؤر استيطانية غير

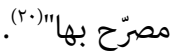
وفي سياق سعي حكومة نتنياهو للحفاظ على البؤر الاستيطانية

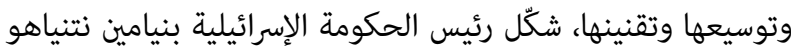

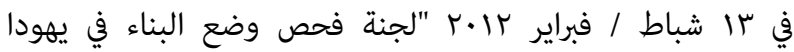
والسامرة" برئاسة القاضي السابق في المحكمة العليا الإسرائيلية والعضو السابق في حزب "حيروت" اليميني المتطرّف، إدموند ليفي،

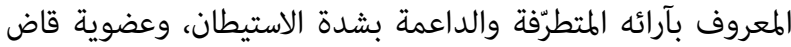

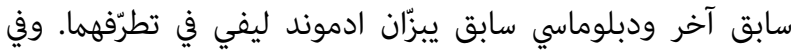

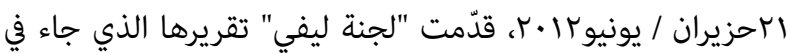

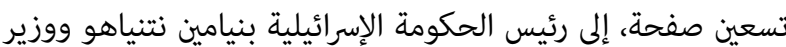

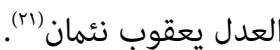

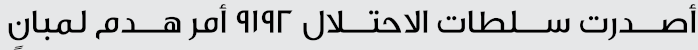
فلسطينية في المنطقة "ج" في السنوات ... Г- ГI. Г.

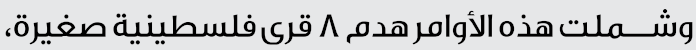
وهدم † بيتًا في قرية سوسيا الفلسطينية

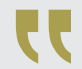

اتّسم تقرير "لجنة ليفي" بالسطحية وبالمغالطات التاريخية والقانونية.

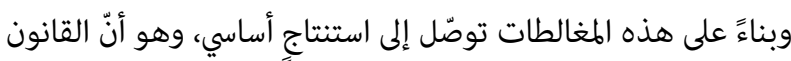

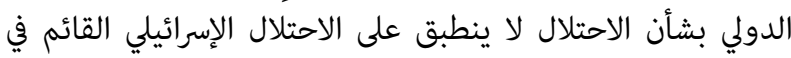

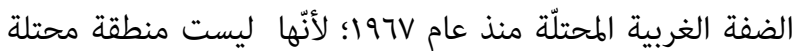

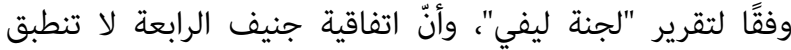

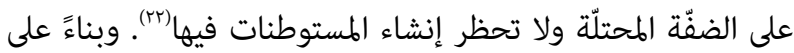
ذلك، قدّم تقرير "لجنة ليفي" جملة من التوصيات بشأن الاستيطان

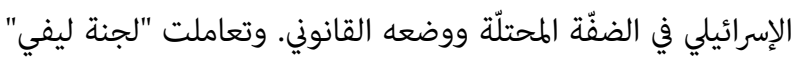

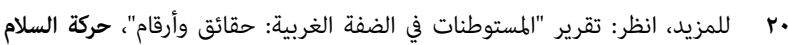

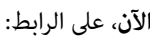
http://peacenowo.org.ilnode/297.

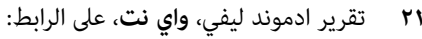
http://go.ynet.co.il/pic/news/09.07.12.pdf

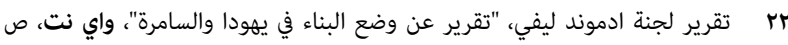

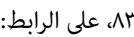

http://go.ynet.co.il/pic/news/09.07.12.pdf
ع. أعلنت سلطات الاحتلال عا٪ من مساحة المنطقة "ج" مناطق

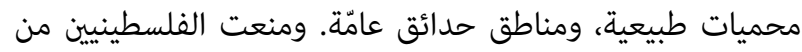

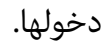
0. منعت سلطات الاحتلال الفلسطينيين من البناء في المنطقة الممتدّة بين جدار الفصل وحدود الرابع من حزيران 197V، والبالغة مساحتها " ب، \% من مساحة المنطقة "ج". 7. أصـدرت سلطات الاحتلال أمـرًا مِنع الفلسطينيين من البناء

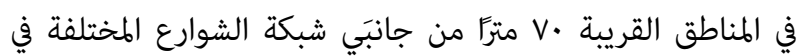

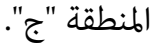
V. تتبع سلطات الاحتلال سياسة التضييق بشدة على الفلسطينيين

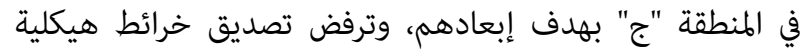

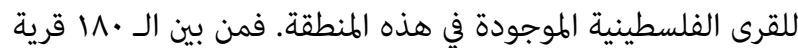
فلسطينية الموجودة في هذه المنطقة هناك خرائط هيكلية لـ 7 اقرية

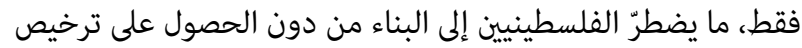

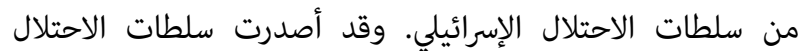

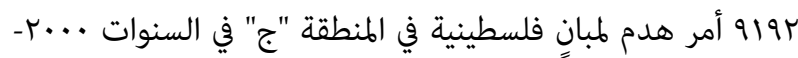

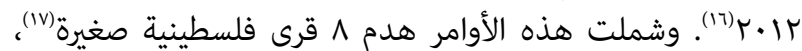

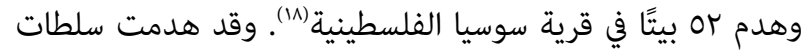

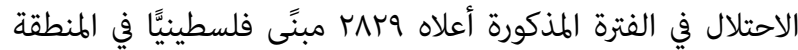

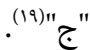

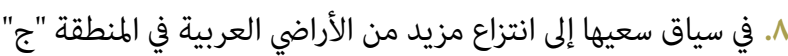
ومصادرتها، أقامت الحكومات الإسرائيلية منذ سنة 1997 أكثر من

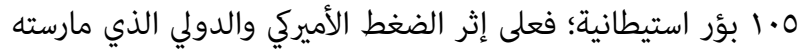

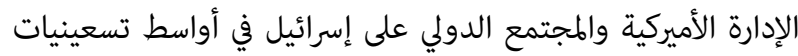

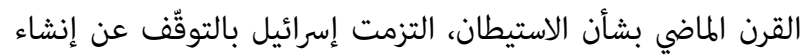

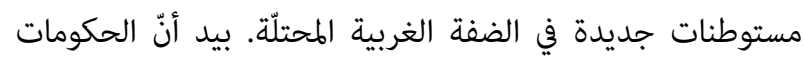

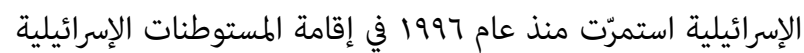

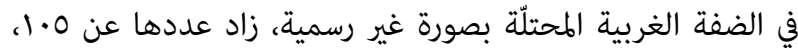

17

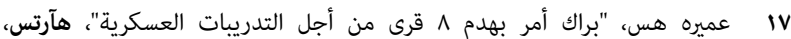

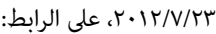
http://.haaretz.co.il/misc/article-print-page/1.1783346

M عميره هس، "الإدارة المدنية أصدرت أوامر بهدم Or بيتا بقرية فلسطينية"، هآرتس،

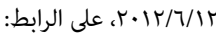
http://www.haaretz.co.il/misc/article-print-page/1.1729927 
• إقامة المزيد من البؤر الاستيطانية في داخل مختلف الأحياء

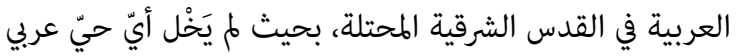
فيها من البؤر الاستيطانية.

• التخطيط والعمل على إقامة مستوطنات يهودية جديدة في

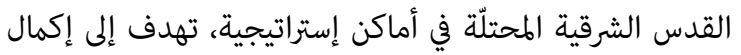
إطباق الحصار الاستيطاني الكامل على القدس الشرقية المحتلة من الجنوب والشرق والشمال.

وكشف تقرير نشرته صحيفة هآرتس في آذار / مارس • • • النقاب

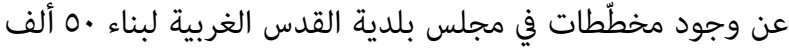
وحدة سكنية يهودية استيطانية في القدس الشرقية المحتلة (م). وأشار

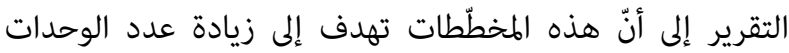

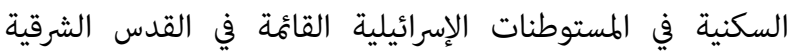

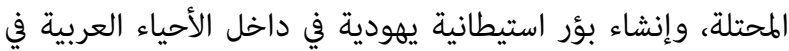

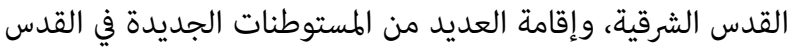
الشرقية المحتلّة.

وقد أعلنت حكومة نتنياهو منذ أن تولّت الحكم في آذار / مارس

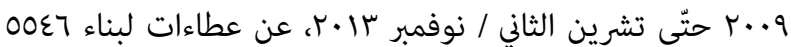
وحدة سكنية استيطانية في المستوطنات في القدس الشرقية المحتلّة،

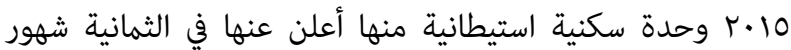

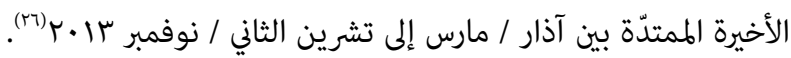
وأقرّت الحكومة الإسرائيلية أيضًا، في الفترة الممتدّة بين 9. +. ب وتشرين

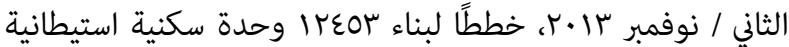

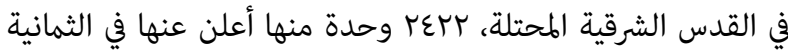

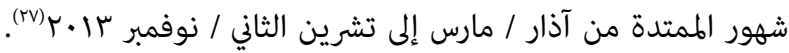

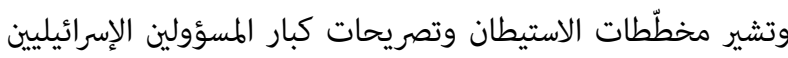

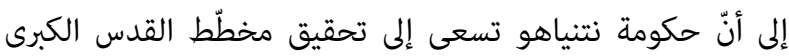

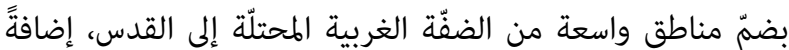

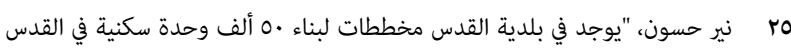

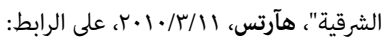
http://www.haaretz.oo.il/misc/article-print-page/1.1192933

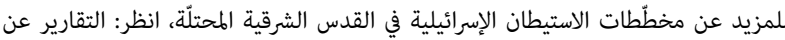

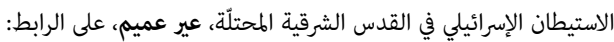
http://www.ir-amim.org.il/?CategoryID=378 .

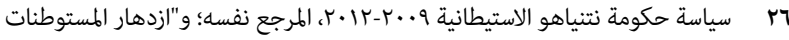
في الثمانية شهور الأولى لحكومة نتنياهو"، المرجع نفسه.

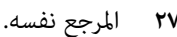

مع الضفة الغربية المحتلة وكأنّها عمليَّا جزء من إسرائيل، ولكن من

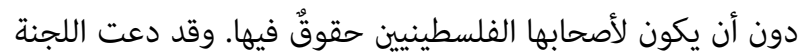

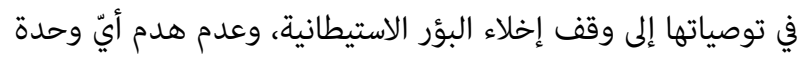

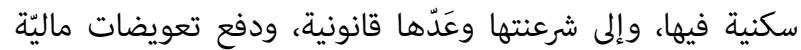
لأصحاب الأرض الفلسطينيين كخيار وحيد من دون الالتفات إلى

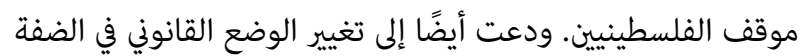
المحتلّة، وإلغاء القوانين والمراسيم والأوامر العسكرية الإسرائيلية

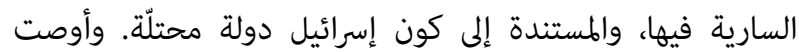
اللجنة بالسماح بإقامة مستوطنات على أراضٍ فلسطينية مصادرة، ودعت إلى إصدار مراسيم تقرّ مناطق نفوذ لجميع المستوطنات

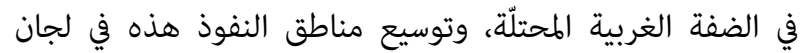

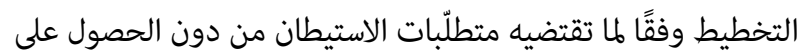
موافقة حكومية. ودعت أيضًا إلى تسجيل جميع الأراضي في الضفّة الضّنة

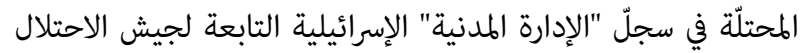

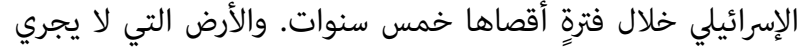

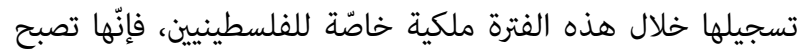

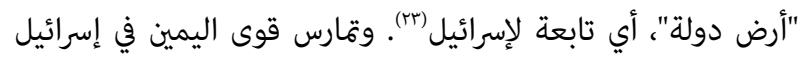

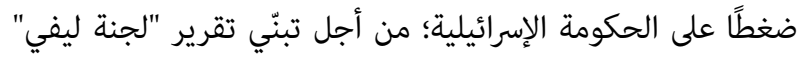

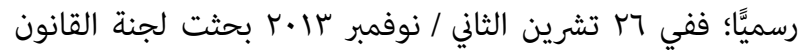

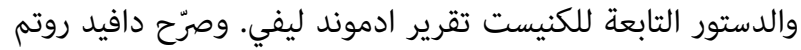

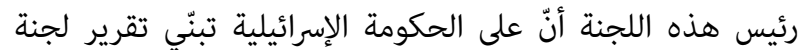

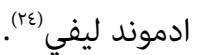

\section{التْوسع الاستْيطانَي فْي منْطْةَ الـقدس الـُشرقِية الـمْمنْلْةُ}

تُولي إسرائيل أهمية قصوى للاستيطان في القدس الشرقية المحتلة،

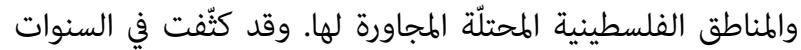

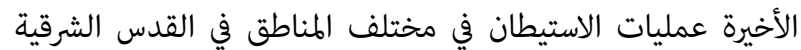
المحتلّة. وشمل ذلك: الممليات الكتيط

• زيادة الاستيطان في المستوطنات الإسرائيلية الستّ عشرة القائة في القدس الشرقية المحتلّة.

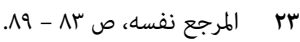

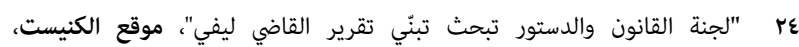

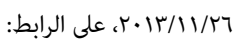

http://www.knesset.gov.il/huka/News.asp?NewsID=680 
• الحصار من الشرق: أعلنت وزارة البناء والإسكان الإسرائيلية في

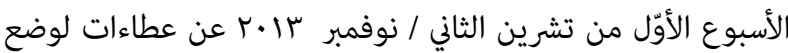

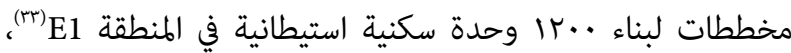

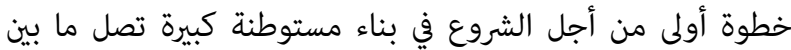

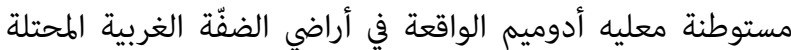
إلى الشرق من القدس الشرقية ومستوطنة التلة الفرنسية والجامعة العبرية القائمة في القدس الشرقية المحتلة. وفي سعيها لإحكام هذا

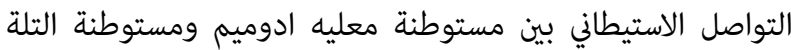

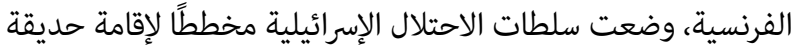
وطنية إلى الغرب من المنطقة E1 على المنحدرات الشرقية لجبل

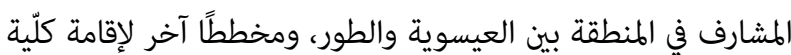
عسكرية على جبل الزيتون.

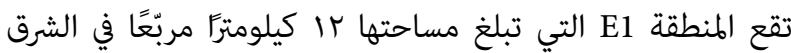

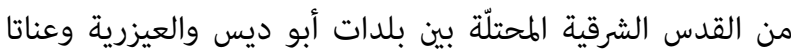

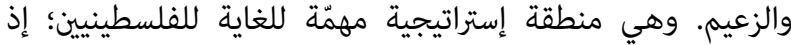

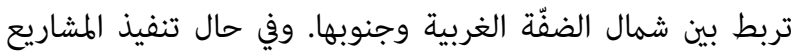
الاستيطانية المشار إليها أعلاه، فإنّها ستفصل نهائيَّا بين شهال الضفال تنفينة الغربية وجنوبها. وكانت حكومة يتسحاك رابين قد ضمّت هذانه

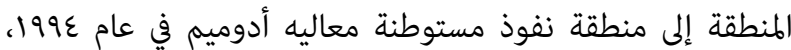
ووضعت المخططات للشروع في بناء مستوطنة فيها. بيد أنّ حكومة

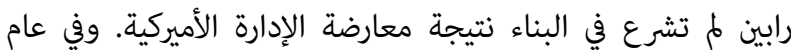

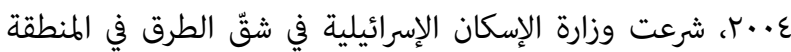

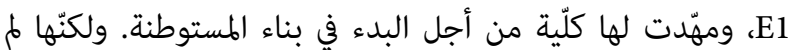

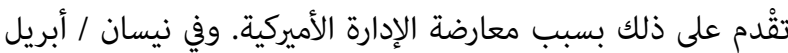

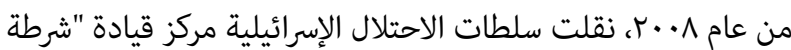

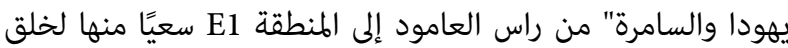

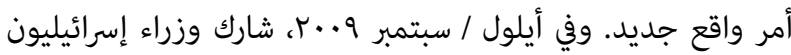

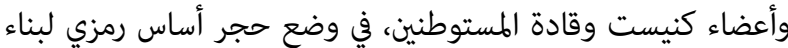
مستوطنة في هذه المنطقة.

وتعتزم سلطات الاحتلال إقامة مستوطنة جديدة في هذه المنطقة

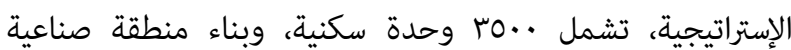

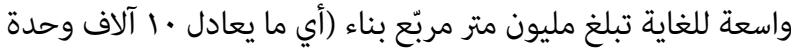

r بـ بـراك رفيد وآخـرون، "عطاءات لبناء عَ ألف وحدة سكنية في الضفة"، هآرتس،

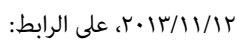
http://www.haaretz.co.il/news/politics/.premium-1.2164180 انظر كذلك إلى: يهونتان ليس وآخرون، "وزارة الإسكان أعلنت عطاءات للبناء في E1 من وراء

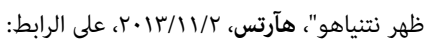
http://www.haaretz.co.il/news/politics/.premium-1.2163926
إلى أراضي القدس الشرقية المحتلة التي ضمّتها إسرائيل إليها في

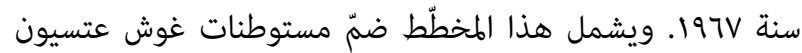

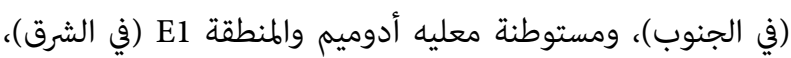

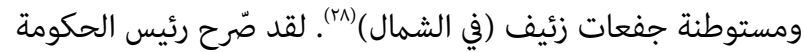

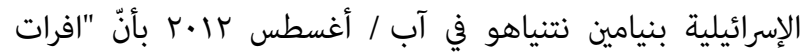

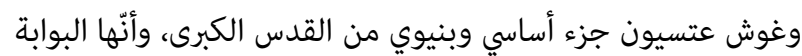

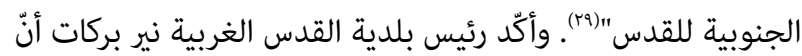

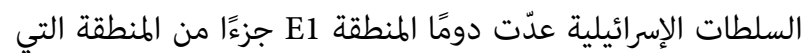

$$
\text { ستتوسّع فيها القدس الكبرى (·•). }
$$

وفي سياق سياستها إطباق الحصار الاستيطاني الكامل على القدس

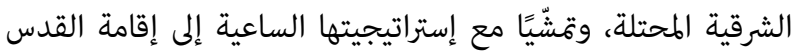

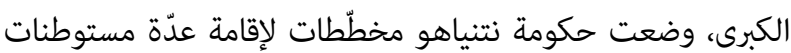
جديدة في جنوب القدس الشرقية المحتلة، وشرقها، وشمالها، كما يلي:

• الحصار من الجنوب: ضاعفت سلطات الاحتلال في عام 11.ب

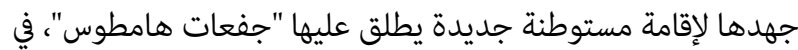
القدس الشرقية المحتلة على أراضي ضاحية بيت صفافا الفلسطينية. ويتكوّن مخطُّط بناء هذه المستوطنة من ثلاث مراحل؛ تشمل الشّل المرحلة الأولى بناء r الب وحدة سكنيّة استيطانية. وقد أقرّت حكومة نتنياهو

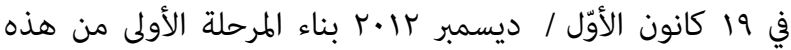

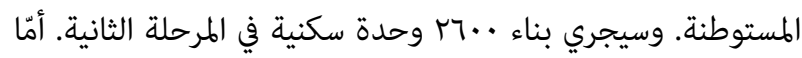
المرحلة الثالثة، فتشمل بناء بآسا وحدة سكنيّة استيطانية (آ). إضافةً إلى ذلك، أقرّت حكومة نتنياهو توسيع مستوطنة جيلو الواقعة في فئناء

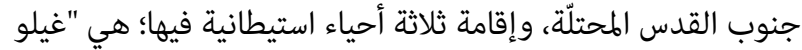

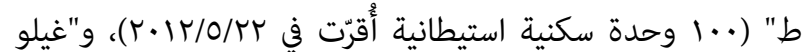

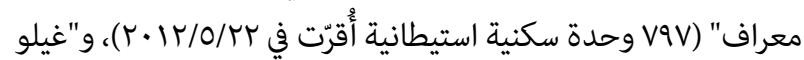

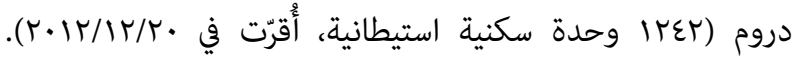

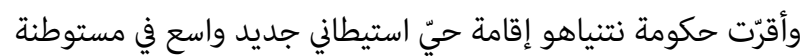

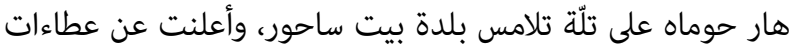
لبناء بهو وحدة سكنية استيطانية في هذا الحيّ الاستيطاني (Fr).

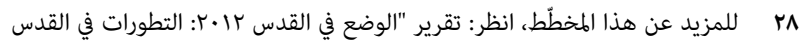

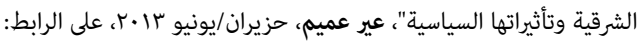
http://goo.gl/ljfiie

$$
\begin{aligned}
& \text { و ب المرجع نفسه. }
\end{aligned}
$$

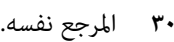

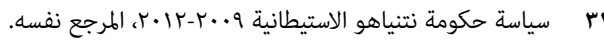

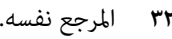


الغائبين" و"إدارة أراضي إسرائيل" وجمعيات استيطانية، مثل "عطيرت

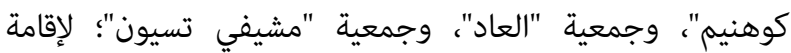
المزيد من البؤر الاستيطانية في قلب الأحياء العربية بغرض وجمعية تهرير

الفلسطينيين منها وتهويدها (†').

وكانت سلطات الاحتلال الإسرائيلية والجمعيات الاستيطانية

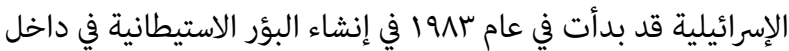

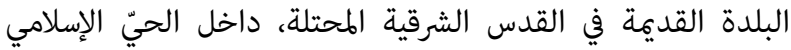

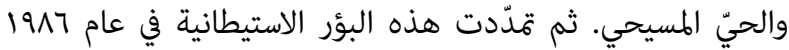

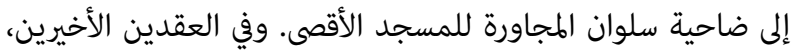

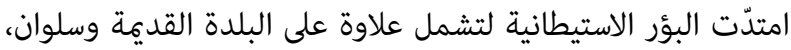
أحياء جبل الزيتون والطور والصوانة وراس العامود ووادي الجوز

$$
\text { والشيخ جراح والطصرارة وبيت حنينا (Pa). }
$$

وتستعمل سلطات الاحتلال الإسرائيلية أساليب وذرائع مختلفة في عملية نزع ملكية البيوت الفلسطينية من أصحابها الفلسطينيين وإخلائهم منها، وفرض سيطرتها عليها، وإحلال مستوطنين مكانهم. ويأتي في مقدمة هذه الأساليب والذرائع استخدام سلطات الاتهات الاحتلال

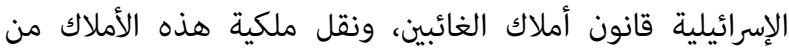

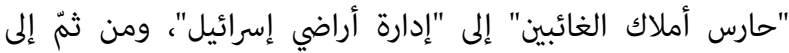

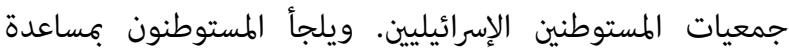
مؤسسات الحكم في إسرائيل إلى إجراءات قضائية، من أجل الئن السيطرة

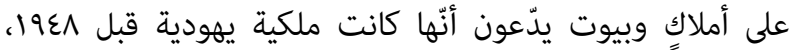

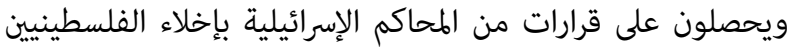

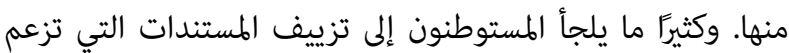

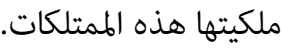

وضاعفت سلطات الاحتلال الإسرائيلية والجمعيات الاستيطانية منذ

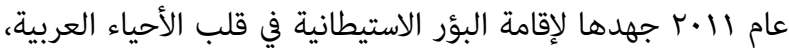

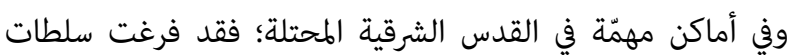

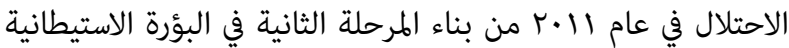

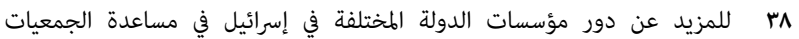

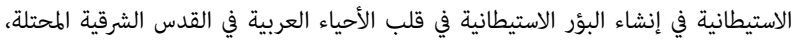

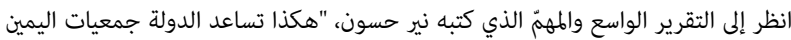

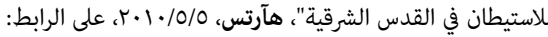
http://www.haaretz.co.il/misc/article-print-page/1.1228499

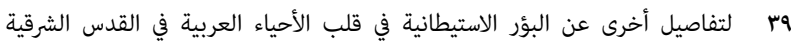

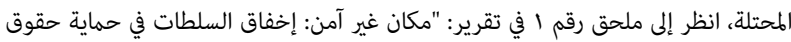

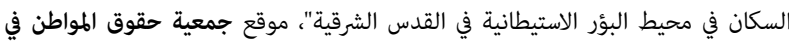

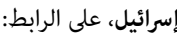

http://www.acri.org.il/pdf/unsafe-space-ar.pdf
سكنية) لفائدة مستوطنة معاليه أدوميم والمستوطنات الإسرائيلية في القدس الشرقية المحتلة، إلى جانب إقامة حديقة واسعة فيها لمصلحة المعانية المستوطنين اليهود (اعَ).

• الحصار من الشمال: في سياق سعيها لتحقيق القدس الكبرى

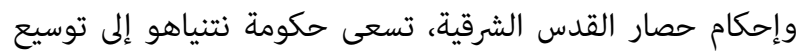

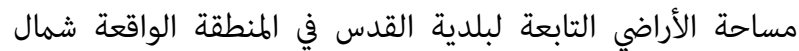

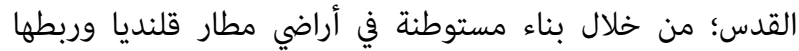

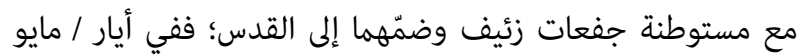

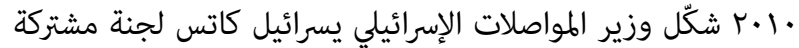

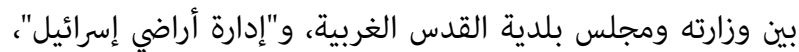

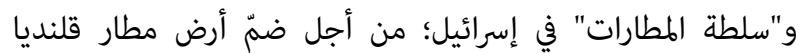

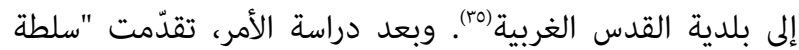

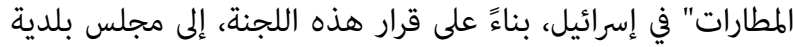

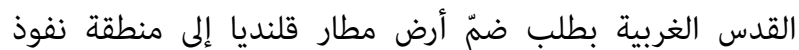

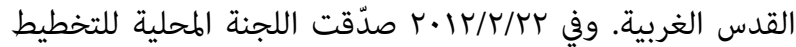

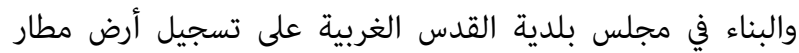

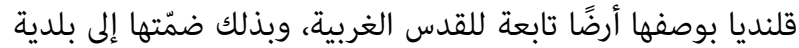

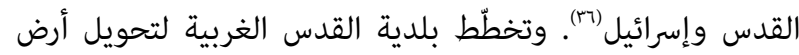

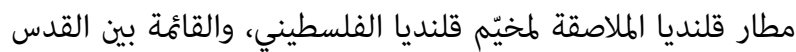
الشرقية المحتلة ورام الله، إلى منطقة صناعية - استيطانية إسرائيلية،

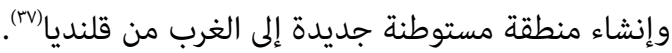

\section{الهجمة الاستيطانية في داخل أحياء الـقدس العربية الـمحنْلة}

كثّفت سلطات الاحتلال في السنوات الأخيرة نشاطاتها لإقامة المزيد

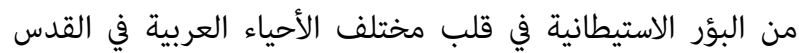

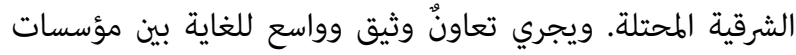
الحكم في إسرائيل، بخاصة بين وزارة الإسكان و"حـارس أملاك

عا ع للمزيد انظر إلى تقرير تحت عنوان "مستوطنة E1 ليست معليه أدوميم"، عير عميم، على الرابط: http://www.ir-amim.org.il/?CategoryID=182

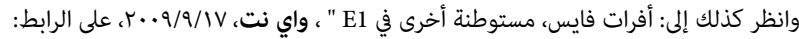
http://www.ynet.co.il/articles/0,7340,L-3773361,00.html

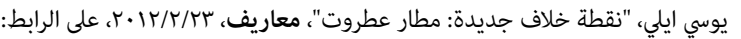
ro http://www.nrg.co.il/online/1/ART2/339/939.html?hp=1\&cat=404

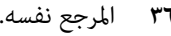
تسفرير رينات، الشرط بفوز بمناقصات الدولة... المرجع نفسه. 
جديد، وفرض حالة من نظام الأبارتهايد على الفلسطينيين وفقًا

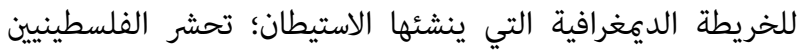

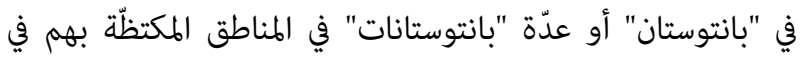
الأراضي الفلسطينية المحتلة، وبذلك تتخلّص ممّا يطلق عليه صهيونيَّا

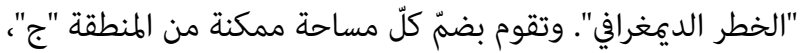
أو معظمها، أو أكبرها. لذلك، ومن منطلقات أيديولوجية - سياسية

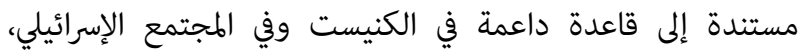

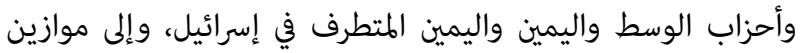
القوى المحلية والإقليمية. لا تريد حكومة نتنياهو التوصّل إلى حلًّ دائم مع الفلسطينيين في الزمن المنظور. وهي لا تطرح أيّ تصوّر لمثل هذا

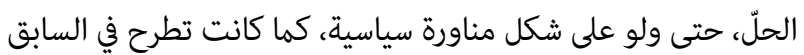

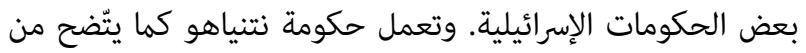
موجات الاستيطان غير المسبوقة التي بادرت إليها في السنوات الأخيرة، التهات

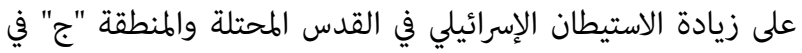

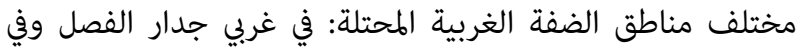

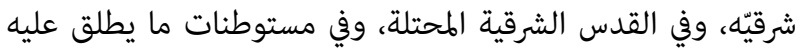

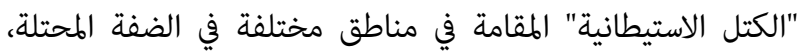

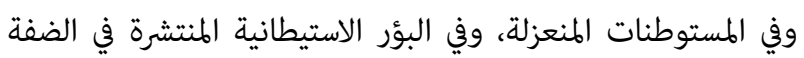

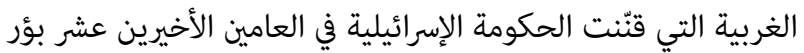

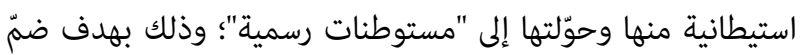

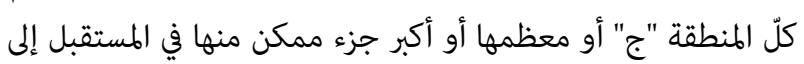
إسرائيل، والتي تشكّل ستّين في المئة من أراضي الضفّة الغربية.

يتناقض الاستيطان في الأراضي الفلسطينية المحتلّة عام $197 V$ مع

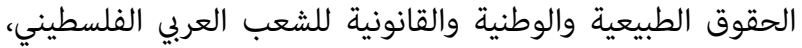

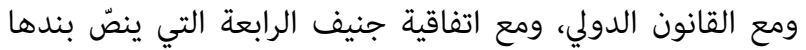

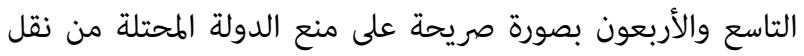

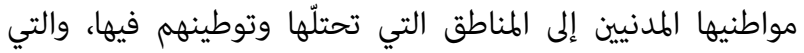

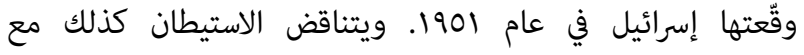
القرارات الصادرة عن مؤسّسات هيئة الأمم المتحدة، ومع مواقف

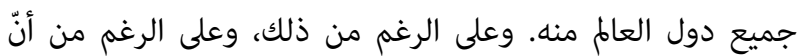

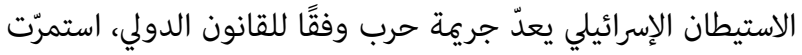

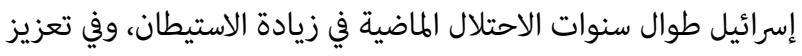

مشروعها الاستيطاني في الضفة الغربية المحتلة.

لقد أقامت إسرائيل في الضفة الغربية المحتلة نظامًا كولونياليَّا - لقارئا

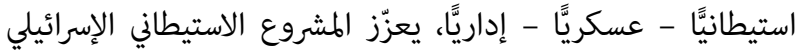

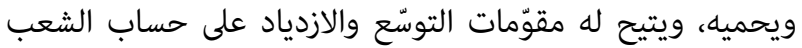

"معليه زيتيم" القائمة في قلب حيّ رأس العامود، والتي شملت بناء •7 وحدة سكنية استيطانية. وشرعت سلطات الاحتلال الإسرائيلية

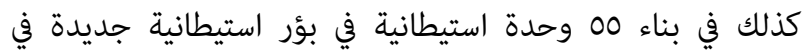

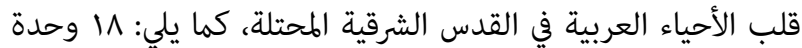
سكنية في بؤرة استيطانية في حيّ الصوانة، و.r وحدة سكنية في بؤرة العردية

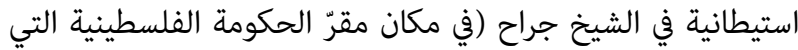

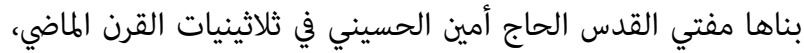

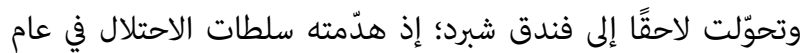

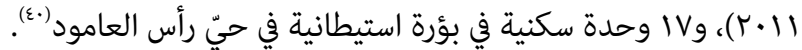
وهناك خطط لإنشاء بؤرة استيطانية في "كرم المفتي" في حيّ الشيخ جراح. وقد جرى نقْل ملكية "حيّ المفتي" بواسطة قانون أملاك

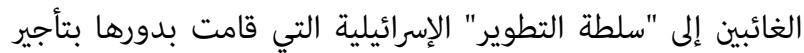
قسم منه لجمعية "عطيرت كوهنيم" الاستيطانية (اع.

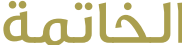

يُعنّ رئيس الحكومة الإسرائيلية بنيامين نتنياهو من أبرز قادة

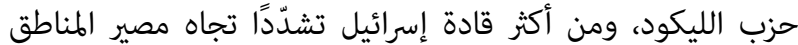

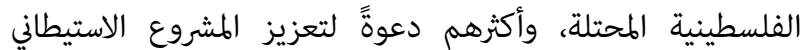

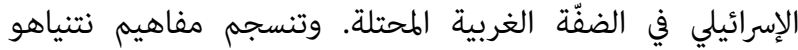

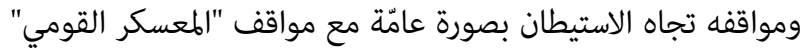

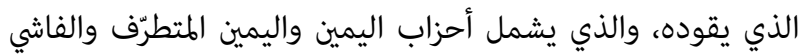

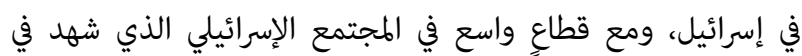

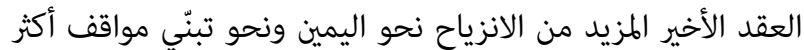

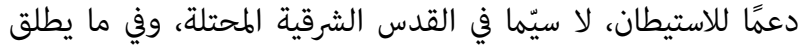

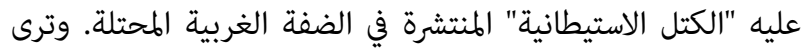

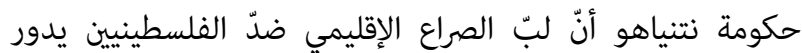
حول مصير أراضي الضفة الغربية المحتلة. وتتمحور إستراتيجيتها،

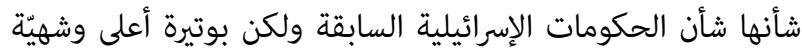

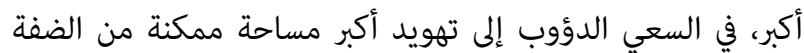

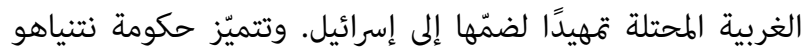
عن الحكومات الإسرائيلية السابقة بأنّ الاستيطان الإسرائيلي في الضفّة الضّنة الغربية المحتلة، بما في ذلك القدس الشرقية المحتلة، هو مشروعها

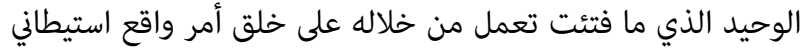

• إع المرجع نفسه.

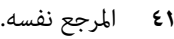


قوّة الشعب العربي الفلسطيني الذاتية والعربية والدولية. إنّ هذا

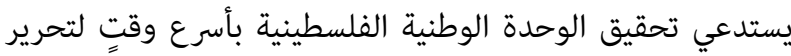

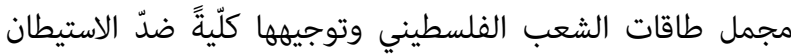

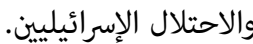

وعلى أرضية النضال الوطني الفلسطيني القائم على برنامج وطني

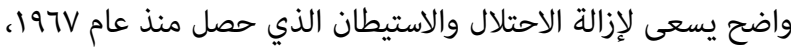

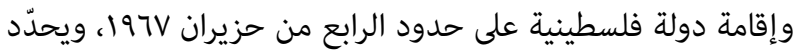

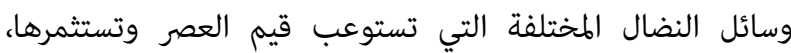
وترفض الاستيطان الكولونيالي والاحتلال والعنصرية الإسرائيلية؛

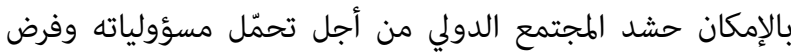
عقوبات مؤلة على إسرائيل ما دامت متمسّكة بالاستيطان والاحتلال.

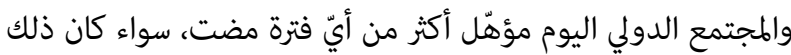

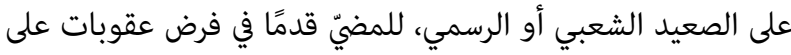

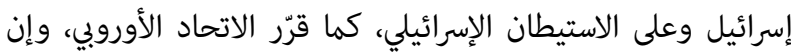

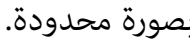

تخشى إسرائيل من أمرين أساسيين في ما يتعلّق بالقضية الفلسطينية،

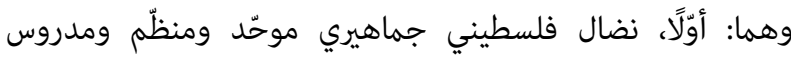

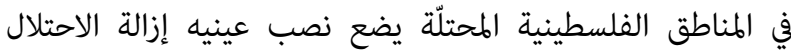
والاستيطان وإقامة دولة فلسطينية على حدود الرابع من حزيران 197V ويعيد طرح القضية الفلسطينية بوصفها قضيّة شعب يعيش

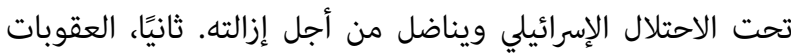

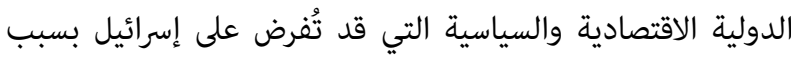

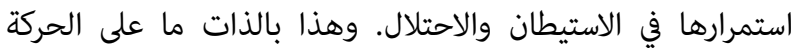
الوطنية الفلسطينية القيام به: نضال وطني جماهيري موحّد ومنظمّم

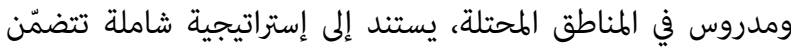

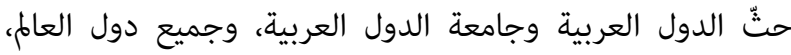

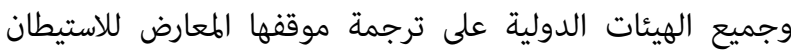

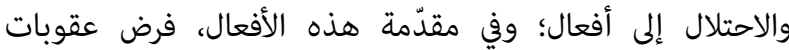

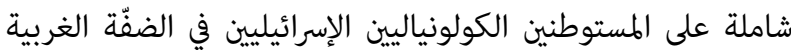

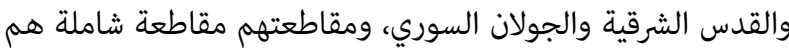
ومؤسساتهم ومنتوجاتهم، بما في ذلك منعهم من دخول أيّ دولة في

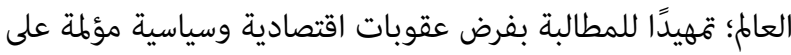
إسرائيل؛ لإرغامها على إزالة الاستيطان والاحتلال.
العربي الفلسطيني وأراضيه وممتلكاته، ويحرمه من استغلال ثرواته وخيراته وتطوير ذاته، ويجعل المستوطنين الكولونياليين الإسرائيليين

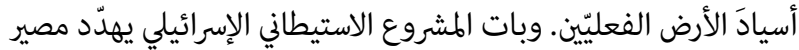

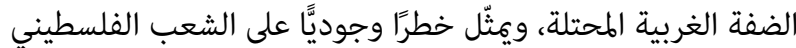
في الضفة الغربية. وتعتزم الحكومة الإسرائيلية المضيّ قدمًا في تعزيز مشروعها الاستيطاني وتوسيعه وزيادته، إلى أبعد مدى ممكن. لقد استفادت إسرائيل في العقدين ونيف الماضيين، من غياب

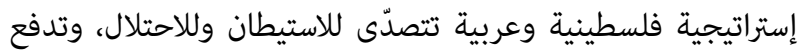
إسرائيل ثمن استمرارها فيهما. واستفادت إسرائيل كثيرًا ممّا يطلق

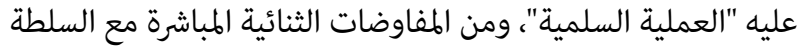
الفلسطينية. واستعملت هذه المفاوضات للاستفراد بالفلسطينيين

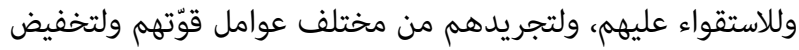

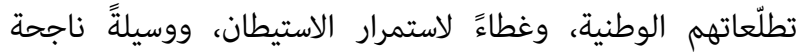

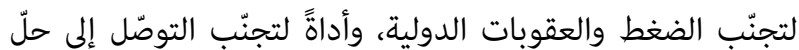
مع الفلسطينيين.

لقد أثتبت التجربة التاريخية في العقود القليلة الماضية أنّ الخضوع

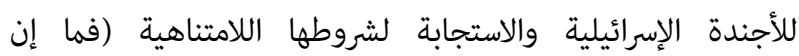

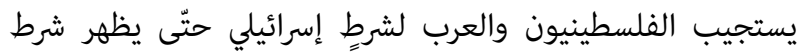

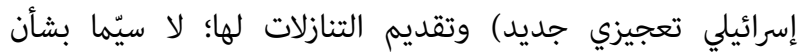
الاستيطان والانسحاب الكامل إلى حدود الرابع من حزيران / يونيو 197V، مل يزد المجتمع الإسرائيلي والحكومات الإسرائيلية إلا تعنًّا

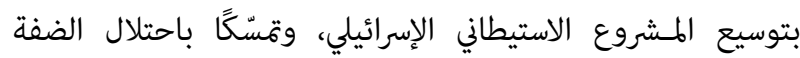

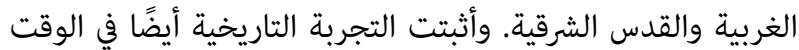

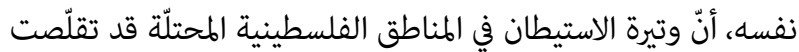

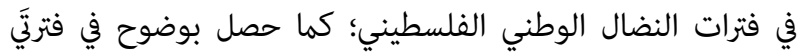

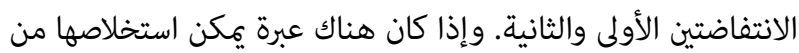

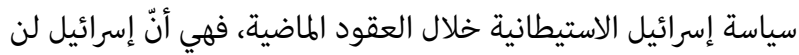

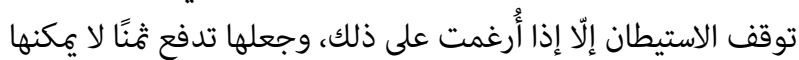
تحمّله أو التعايش معه. وهذا يقتضي من قيادة السلطة الفلسطينية وقيادة مختلف التنظيمات والفعاليات الفلسطينية وقفة حقيقية

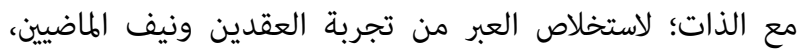

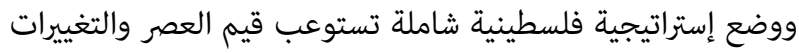
الجارية في المنطقة وتستند إليها؛ إستراتيجية مقدورها تفئها تفعيل عوامل 


\section{العلاقات المغربية الجزائرية: العقدة الجيوستراتيجية}

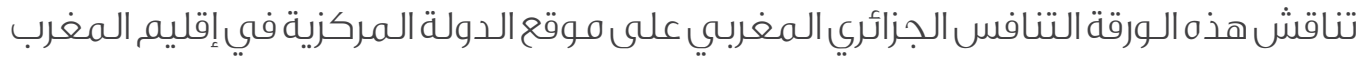

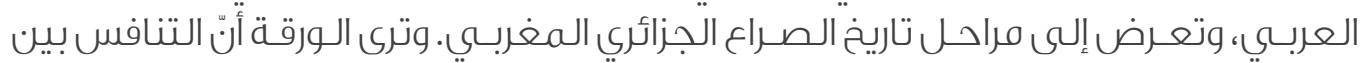

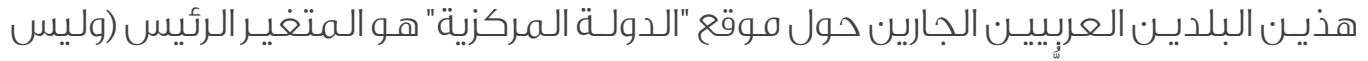

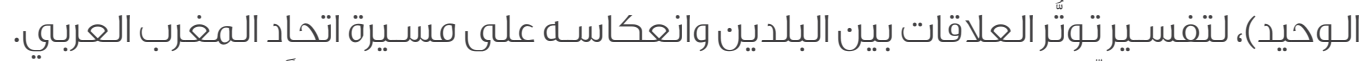
وترى الورقة أن كلّ مظاهر الصراع بين البلدين ليست إلا تعبيراتِ مختلفةً يختفي كلها وراء هذا المتغير الرئيس. يضاف إلى ذلك أنّ التوازن النسبسي في موازين القوى بـين بين البلدين هو

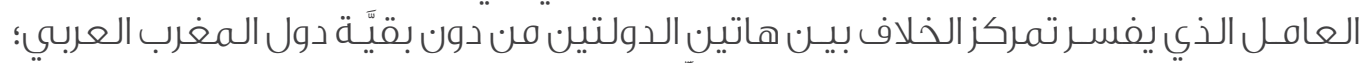
إذ إنّ تونـس وليبيـا ومـوريتانياتدرك جيدًا أنّ كلًا منها لا تمتلك مؤهلات احتلال موقع "الدولة 